\title{
EDITORIAL
}

\section{Current and future relevance of guidelines}

\section{W W Klein}

There is a widely held belief that guidelines improve the quality of care for patients. However, there is also potential for harm, as any attempt to standardise care ignores the heterogeneity of patients and the complexity of medical decisions

Correspondence to: Professor Werner Klein, Medizinische Universitatsklinik Graz, Klinische Abteilung fur Kardiologie,

Auenbruggerplatz 15, A-8036 Graz, Austria; we.klein@kfunigraz.ac.at
$\mathrm{O}$ ver the past 20 years, practice guidelines have become an increasingly popular tool for synthesis of clinical information. Clinical practice guidelines are commonly defined as systematically developed statements to assist practitioner and patient decisions about appropriate health care for specific clinical circumstances. ${ }^{\perp}$

The objectives of guidelines are to enhance appropriateness of practice, improve quality of cardiovascular care, lead to better patient outcomes, improve cost effectiveness, help authorities to decide on the approval of drugs and devices, and identify areas of research needed. Guidelines may also be used as quality measurement for health insurance. We know from the Euro Heart Survey ${ }^{2}$ that practice varies from country to country in Europe, providing a rationale for achieving a common standard of care for cardiovascular diseases.

A profusion of guidelines has been issued in recent years by different organisations-the European Society of Cardiology (ESC), the American Heart Association, the American College of Cardiology, and other related societies. By means of links to websites of national societies, several hundred guidelines are available. ${ }^{3} 4$ This profusion can put at stake the authority and validity of guidelines which can only be guaranteed if they have been developed by an unquestionable decision making process. This is one of the reasons why the ESC and others have issued recommendations for formulating and issuing guidelines which are quoted as the preamble or appendix in the final reports. ${ }^{5}$

\section{BENEFITS AND HARMS}

The enthusiasm over practice guidelines stems from the widely held belief that they improve the quality of care. ${ }^{6}$ By promoting clinical practices of proven effectiveness, guidelines can help to optimise patient outcomes and discourage the performance of ineffective or harmful interventions. Adherence to guidelines can improve the consistency of care, so that patients with similar conditions will be treated according to the same protocol regardless of where, or from whom, they receive care. Guidelines developed from a systematic review of the evidence focus attention on gaps in the evidence and thereby help prioritise future research. Guidelines can help avoid inefficiencies and optimise the value of healthcare expenditures by identifying practices that are unnecessary or unduly expensive.

There are, however, potential harms from practice guidelines. The attempt to standardise care ignores the heterogeneity of patients and the complexity of medical decisions. The clinical circumstances of each patient may mean that recommendations that are reasonable for patients as a whole may be inappropriate for specific individuals. The encouragement, if not requirement, of physicians to comply with recommendations may mean that the interest of patients with special circumstances may either be sacrificed to achieve compliance, or, alternatively, that both clinician and patient may face inconveniences (or more punitive action) for deviating from the guidelines. Practice guidelines can create medicolegal difficulties by setting an arbitrary standard of care that can be cited in court. Guidelines that advocate expensive tests and treatments can, by increasing costs, frustrate the efforts of those who wish to control expenditures.

\section{CURRENT QUALITY OF GUIDELINES}

There is an increasing concern about the quality, reliability, and independence of practice guidelines. Recent reviews $\mathrm{s}^{7-9}$ have shown that in spite of improvement over time, the quality of practice guidelines developed by specialty societies is unsatisfactory. Most of them do not adhere well to established methodological standards and the greatest improvement is needed in the identification, evaluation, and synthesis of the scientific evidence (table 1). Guidelines must accurately describe the quality of the evidence and the degree of uncertainty that underlie the recommendations.

\section{KEY STEPS IN GUIDELINE DEVELOPMENT}

The methods for developing evidence based practice guidelines include the following steps:

- Definition of topic and process

- Assessment of clinical benefits and harms

- Review of the scientific evidence

- Consideration of expert opinion

- Consideration of resource and feasibility issues

- Development of recommendations

- Writing the guideline

- Outside review $^{7}$

\section{ESC GUIDELINE PROGRAMME}

The ESC started to produce guidelines in 1994. The Committee for Scientific and Clinical Initiatives was installed and the position document 
Table 1 Number of guidelines that met the three quality criteria according to year of publication. ${ }^{8}$

\begin{tabular}{llllll}
\hline & $\begin{array}{l}1988-91 \\
(n=48)\end{array}$ & $\begin{array}{l}1992-93 \\
(n=81)\end{array}$ & $\begin{array}{l}1994-95 \\
(n=125)\end{array}$ & $\begin{array}{l}1996-98 \\
(n=177)\end{array}$ & $p$ For trend \\
\hline $\begin{array}{l}\text { Full description of } \\
\text { professionals }\end{array}$ & $6(12 \%)$ & $9(11 \%)$ & $11(9 \%)$ & $27(15 \%)$ & 0.99 \\
$\begin{array}{l}\text { Search undertaken } \\
\begin{array}{l}\text { Grading of } \\
\text { recommendation }\end{array}\end{array}$ & $1(2 \%)$ & $4(5 \%)$ & $14(11 \%)$ & $32(18 \%)$ & $<0.001$ \\
\hline
\end{tabular}

"Recommendations for task force creation and report writing" was published in 2000 .

Currently, the Committee for Practice Guidelines and Policy Conferences supervises and coordinates the preparation of new guidelines and expert consensus statements produced by task forces, expert groups, and consensus panels. The committee is also responsible for the endorsement of these guidelines or statements.

Several types of guidelines are possible: health condition or disease related guidelines, procedure related guidelines, and diagnosis related guidelines. The subject chosen for guidelines are usually broad issues within the discipline of cardiology, which are neither too technical nor too specific in nature. The subjects chosen for expert consensus statements are not so broad and focus more on specific topics, such as drugs and devices.

The selection of topics is a long process and may take up to three months. The Committee for Practice Guidelines is responsible for seeking the advice of the working group chairman and presidents of national societies. In order to install a long term plan, the ESC undertook an inventory of all existing guidelines in different European countries on different topics published during the past few years (fig 1). A large number of guidelines have been published on several topics, such as myocardial infarction, epidemiology and prevention, and arrhythmias. On the other hand, a number of important top- ics like cardiomyopathies, valvar heart disease or peripheral vascular disease are under represented.

Looking at the number of published guidelines per year since 1985 (fig 2), one finds a steep increase in recent years. On average, a larger European country (fig 3 ) produces about five guidelines per year, while a smaller European country usually uses the European guidelines, with or without amendments.

The growth in the number of guidelines without application of rigorous criteria for their production could undermine the credibility and lead to harm to the patient if the wrong recommendations are put into practice. In order to overcome the problem of simultaneous guideline production by different societies in different European countries and to enhance the quality of guidelines, the Committee for Practice Guidelines and Policy Conferences has established a long term European plan for the coming 3-4 years (table 2).

In the future, national societies should send in their best suited guidelines to the Committee for Practice Guidelines. By the addition of external expert opinions, these can then be raised to official European guidelines. The same is applicable to working groups. Recommendations produced by working groups can be raised to a European guideline if of interest. This process would guarantee coverage of the broad field of cardiovascular medicine, while at the same time avoid unnecessary duplication of guidelines in different countries.
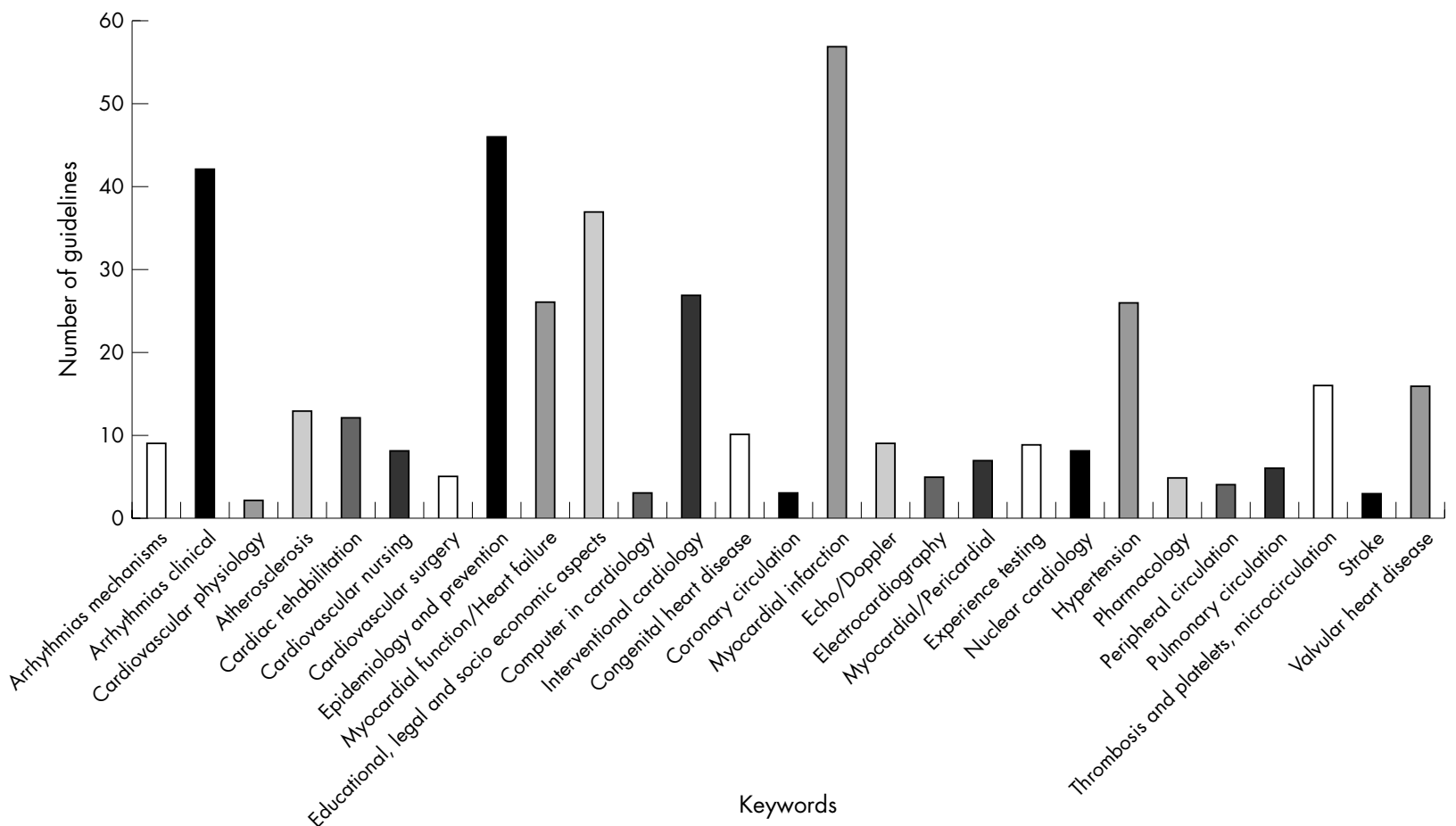

Figure 1 Number of guidelines per keyword. 


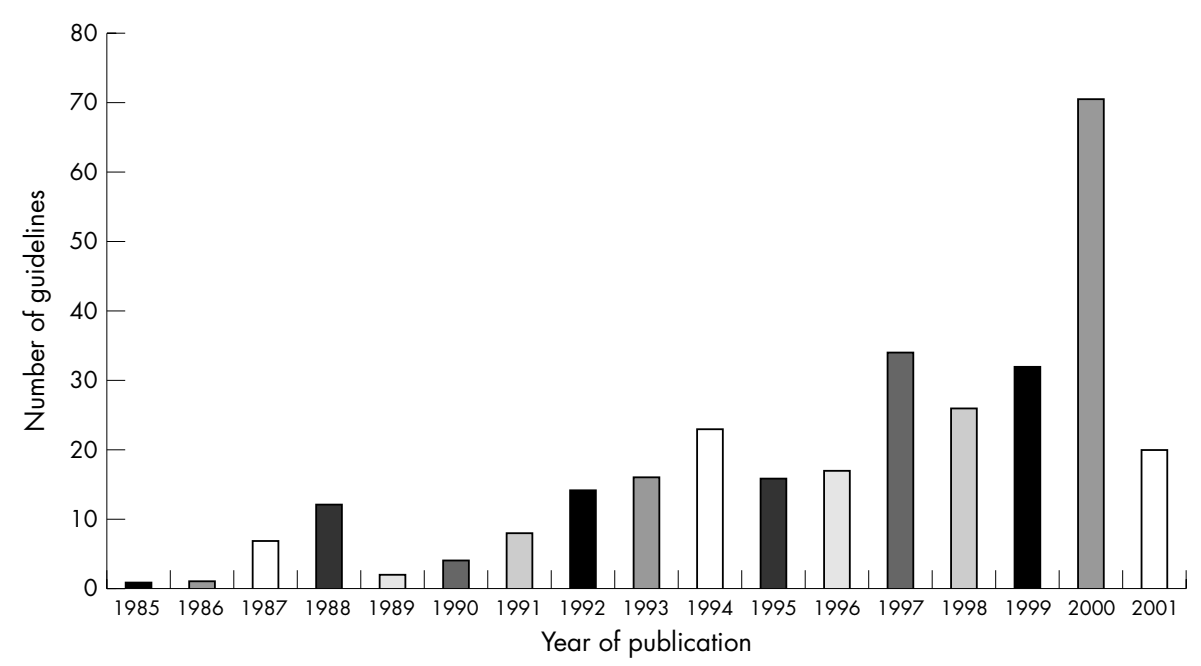

Figure 2 Number of guidelines published per year since 1985.

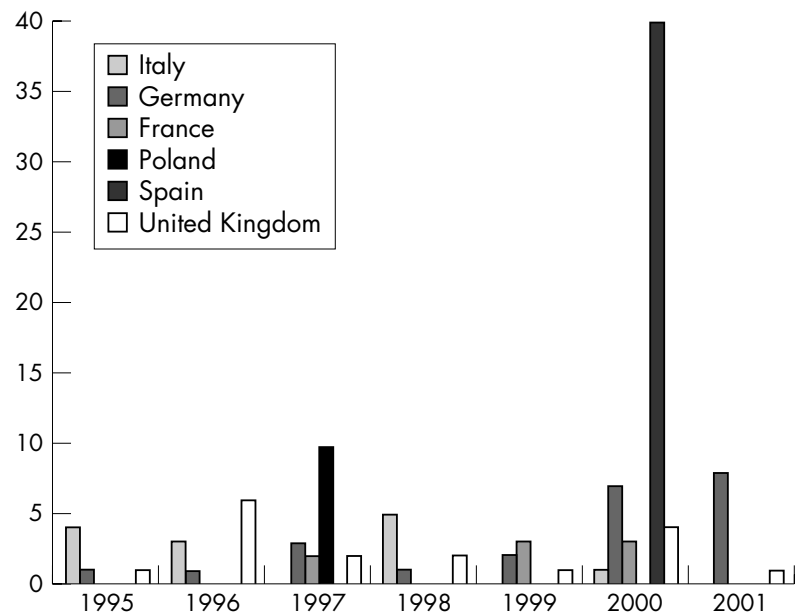

Figure 3 Number of guidelines produced by country since 1995.

On the other hand, European guidelines, when developed, should be discussed on a regular basis with experts from national societies. After the input of all national societies, these guidelines can then be endorsed by these societies across Europe.

\section{ADHERENCE TO GUIDELINES}

Even though guidelines define optimal medical care, studies consistently show that they are unlikely to be effective in changing practice behaviour, unless the production of the recommendations is coupled with an effective implementation strategy. Of these, perhaps the most important is the active involvement of the local providers who will be responsible for implementing these guidelines. Other important tools include audit and feedback, reminder systems, and patient involvement. Evaluation studies are also necessary to determine whether the guidelines are being used and lead to improved outcome.

The adherence to guidelines should be evaluated by surveys. If there are gaps in translating best practice to the bedside, these should be filled in with pinpointed education. The ESC has developed a programme of coordination between guidelines, surveys, and education. On the other hand, all published European guidelines and expert consensus documents should be endorsed by national societies and amended if there is a need for amendment.

Guidelines are becoming increasingly popular among physicians. In the future, the gap between research results and best practice will be closed with adequate educational programmes. The differences between the experts interpreting the research results and that which is achieved by traditional continuing medical education, monograph risk charts, public education, translation to local languages, and information to policy making organisations.

The quality of guidelines will be measured by the effect it is having on people.

For quality measurement it is necessary to get feedback from practice and possibly to correct the evidence if necessary. In the future, this will be an ongoing cycle between evidence, guidelines, and practice.

\section{PUBLICATION OF GUIDELINES}

Guideline documents may be published in several formats, including a short version for busy clinicians which encapsulates the recommendations, a lengthy monograph which summarises the scientific evidence and rationale, and a consumer version for the patient.

Up until now, the European guidelines have been published in the European Heart Journal in full. This may become a problem in the near future, since the guidelines comprise up to 100 pages including an exhaustive literature compendium. This would exceed the capacity of the journal. In the future, therefore, we will publish executive summaries (up to 10 pages) in the journal as soon as the guidelines are developed and at the same time put the full text of the guidelines on the website. Coinciding with the ESC annual congress, all guidelines developed during the respective year will be published in a supplement to the journal. Cardiologists will therefore have an archive of all new and updated guidelines in one booklet.

\section{FUTURE RELEVANCE OF GUIDELINES}

In the future, the number of guidelines on the management of cardiovascular disease will be reduced. There will be regular updates on the main topics (stable angina, unstable angina, myocardial infarction, hypertension, valvar heart disease, etc), the quality of the guidelines will improve by fulfilling all quality criteria, and adherence to methodology of standards and clear recommendations will be given.

The evidence will be improved by a substantial number of trials in the future, and in-depth checks to see if the guidelines are being followed and if care is improved, as has already been shown with the guidelines on prevention ${ }^{20}$ and the guidelines on acute coronary syndromes. ${ }^{11}$

Practice guidelines should advocate the best options for patients. Also, everyone in the healthcare system surely endorses this goal-private hospitals and health plans concerned about profit margins, and government agencies 
Table 2 Guideline publication schedule of the European Society of Cardiology

\begin{tabular}{|c|c|c|c|c|}
\hline Title of guidelines & 2001 & 2002 & 2003 & 2004 \\
\hline Guidelines on diagnosis and management of aortic dissection & $X$ & & & \\
\hline Guidelines on management of syncope (diagnosis and treatment) & $x$ & & & \\
\hline Guidelines on sudden cardiac death & $x$ & & & \\
\hline Updated guidelines on diagnosis and treatment of chronic heart failure & $x$ & & & \\
\hline Guidelines on management of patients with atrial fibrillation (joint task force with ACC and AHA) & $\mathrm{X}$ & & & \\
\hline Guidelines on management of infective endocarditis & & $x$ & & \\
\hline Guidelines on management of grown-up congenital heart disease & & $\mathrm{x}$ & & \\
\hline Guidelines on management of primary pulmonary hypertension & & $x$ & & \\
\hline Guidelines on management of chest pain & & $x$ & & \\
\hline Guidelines on management of supraventricular arrhythmias (joint task for with $\mathrm{ACC}$ and $\mathrm{AHA}$ ) & & $x$ & & \\
\hline Updated guidelines on acute myocardial infarction & & $x$ & & \\
\hline Expert consensus document on management of pericardial diseases & & $x$ & & \\
\hline $\begin{array}{l}\text { Expert consensus document on neonatal electrocardiography (interpretations and guidelines for } \\
\text { management) }\end{array}$ & & $x$ & & \\
\hline Expert consensus document on appropriate use of $\beta$ blockers and ACE inhibitors & & $\mathrm{X}$ & & \\
\hline Expert consensus document on hypertrophic cardiomyopathy (joint task force with ACC and AHA) & & $X$ & & \\
\hline Expert consensus document on anti-thrombotic treatment & & $x$ & & \\
\hline Guidelines on percutaneous coronary intervention & & & $x$ & \\
\hline Updated guidelines on prevention of cardiovascular disease (3rd task force of Joint European Societies) & & & $x$ & \\
\hline Updated guidelines on acute coronary syndromes without persistent ST segment elevation & & & $x$ & \\
\hline Expert consensus document on management of cardiac diseases during pregnancy & & & $x$ & \\
\hline Expert consensus document on management of acute heart failure & & & $\mathrm{X}$ & \\
\hline Guidelines on management of arterial hypertension (joint task force) & & & & $X$ \\
\hline Guidelines on management of cardiovascular problems in diabetics & & & & $X$ \\
\hline Guidelines on management of valvular heart disease & & & & $x$ \\
\hline Expert consensus document on hormone replacement therapy & & & & $x$ \\
\hline
\end{tabular}

struggling to finance medical care, must give greater attention to cost considerations than would individual patients and clinicians. This has created a lucrative market for the commercial vending of practice guidelines that trim costs, reduce in-hospital length of stay, and increase efficiency sometimes at the expense of the patient. Private vendors and consulting firms have seized this opportunity by selling guidelines, with glossy promotional materials and computer software, to managed care organisations and hospital systems, which assume that they are buying protocols for high quality care.

As advocates for patients, physicians and physician organisations like the ESC have a professional and a social responsibility to insist that such practice guidelines, which are being implemented by health plans across Europe on millions of enrollees, provide adequate disclosure of the process by which they were developed.

The "black box" from which such guidelines are generated must be opened to determine the degree of science and uncertainty on which they are based. Only then can patients, providers, and payers know whether they are receiving, providing, or purchasing optimal care or whether, under the disguise of "quality" or "efficiency", optimal health is being traded off in the interest of other agenda.

In the future, official guidelines of the ESC should be the relevant guidelines for cardiovascular care in all European countries. Ideally, the patient with unstable angina admitted to hospital in the Ukraine and in the Netherlands will get identical, optimal medical care by following these guidelines.

\section{REFERENCES}

1 Institute of Medicine. Field M, Lohr KN, eds. Clinical practice guidelines: directions of a new program. Committee to advise the public health service on clinical practice guidelines. Washington DC: National Academy Press, 1990.

2 EUROASPIRE Study Group. Clinical reality of coronary prevention guidelines: a comparison of EUROASPIRE I and II surveys in nine countries. Lancet 2001;357:997-1003.

3 Hibble A, Kanka D, Pencheon D, et al. Guidelines in general practice: the new Tower of Babel? BM 1998;317:862-3

4 European Society of Cardiology. Scientific publications and guidelines. Guidelines for patients management, study groups, cardiology guidelines by topic. URL: http: \Iwww.escardio.org

5 European Society of Cardiology. Recommendations for task force creation and report production. A document for task force members and expert panels responsible for the creation and production of guidelines and expert consensus statements. Committee for practice guidelines \& policy conference (CPGPC). 2001

6 Field MJ, Lohr KN, eds. Guidelines for clinical practice: from development to use. Institute of Medicine committee on clinical practice guidelines. Washington DC: National Academy Press, 1992.

7 Woolf S. Do clinical practice guidelines define good medical care? The need for good science and the disclosure of uncertainty when defining best practices. Chest 1998;113:166S-71S.

8 Grilli R, Magrini N, Penna A, et al. Practice guidelines developed by specialty societies; the need for a critical appraisal. Lancet 2000;355: 103-6.

9 Shaneyfelt T, Mayo-Smith M, Rothwangl J. Are guidelines following guidelines? The methodological quality of clinical practice guidelines in the peer-reviewed medical literature. JAMA 1999;281:1900-5.

10 EUROASPIRE II Group. Lifestyle and risk factor management and use of drug therapies in coronary patients from 15 countries. Principal results from EUROASPIRE II. Eur Heart J 2001;22:554-72.

11 Battler A, et al. Euro Heart survey over acute coronary syndromes (ESACS). Eur Heart J (in press) 